\title{
Genetic and Demographic Outcomes in a Population of Patients with Headache and Facial Pain
}

\author{
Jonathan Eskenazi1, Miriam Nuno², Steven Graff-Radford ${ }^{3 *}$, Oana M. Dumitrascu1\# \\ ${ }^{1}$ Department of Neurology Cedars-Sinai Medical Center, Los Angeles, CA, USA \\ ${ }^{2}$ Department of Public Health Sciences, Division of Biostatistics, University of California Davis, Davis, CA, USA \\ ${ }^{3}$ The Pain Center, Cedars-Sinai Medical Center, Los Angeles, CA, USA \\ Email: "oana.dumitrascu@cshs.org
}

How to cite this paper: Eskenazi, J., Nuno, M., Graff-Radford, S. and Dumitrascu, O.M. (2018) Genetic and Demographic Outcomes in a Population of Patients with Headache and Facial Pain. Journal of Behavioral and Brain Science, 8, 339-350.

https://doi.org/10.4236/jbbs.2018.86022

Received: April 18, 2018

Accepted: June 3, 2018

Published: June 6, 2018

Copyright $\odot 2018$ by authors and Scientific Research Publishing Inc. This work is licensed under the Creative Commons Attribution International License (CC BY 4.0).

http://creativecommons.org/licenses/by/4.0/

\begin{abstract}
Background: Pharmacogenetics information about cytochrome p450 (CYP450) polymorphism in patients with headaches is limitedly reported. Similarly, the genetic factors linking various headache types and vascular disorders are poorly described. We aimed to characterize the genetic profile of a cohort of headache and facial pain subjects. Methods: Medical records of consecutive headache subjects that underwent PersonaGene ${ }^{\mathrm{TM}}$ testing were reviewed. PersonaGene ${ }^{\mathrm{TM}}$ panel assessed CYP450, apolipoprotein E (ApoE), methylene tetrahydrofolate reductase (MTHFR), Factor II, Factor V Leiden and Vitamin K epoxide reductase complex subunit 1 (VKORC1). Demographic information, headache diagnosis and genetic profiling were analyzed and compared with data obtained from the general population. Results: Out of 130 headache patients, $91.3 \%$ were Caucasian and $70.8 \%$ had migraine. Compared to the general Caucasian population, our Caucasian headache patients were significantly different for CYP3A4/A5 and CYP2D6 ( $\mathrm{p}<0.001)$ and comparable regarding CYP2C9 and CYPC19. Whereas MTHFR genotype was similar, ApoE and Factor V Leiden were different in headache patients $(p=0.001)$. Less headache patients showed intermediate sensitivity to warfarin $(p=0.009)$ based on VQORC1 genotyping. No differences were noticed between migraine and other headache type diagnoses for all the genetic tests. Conclusion: Distinctive profiles for CYP450, ApoE, Factor V Leiden and VQORC1 were observed in our Caucasian headache cohort. These results may impact headache subjects' pharmacological treatment options and vascular risk ascertainment.
\end{abstract}

\section{Keywords}

Headache, Pharmacogenetics, Cytochrome P450, Cerebrovascular Risk,

${ }^{\star}$ Deceased. 


\section{Introduction}

Headache and facial pain are common disorders with multifaceted pathophysiology that often pose therapeutic challenges. Migraine headache is a complex hereditary neurovascular condition that is caused by a combination of environmental and genetic factors [1] [2]. The association between migraine and unfavorable cardiovascular risk profile and cerebrovascular disorders is recognized, with various hypotheses being conveyed to explain the underlying mechanisms [3] [4]. Pathophysiological studies suggest that genetic factors may play a role in this linkage [5]. If the relationship between Apolipoprotein E (ApoE), methylene tetrahydrofolate reductase (MTHFR), Factors II and V Leiden and cardiovascular and cerebrovascular risk is reported, the connection between these factors and headaches is less studied. Conversely, there is no current evidence to support that migraine preventative therapy decreases the risk of further vascular events [6]. On another side, pharmacogenetics data deriving from patients suffering from headaches are limited, despite discerning that cytochrome P450 (CYP450) enzymes polymorphism affects pharmacogenetics and pharmacodynamics of headache therapies and potentially correlates with the therapeutic outcomes [7]. CYP450 genetic analysis spectrum as well as targeted therapies based on the metabolic substrate and genetic testing is not well described, despite being potentially very useful tools in headaches management.

To better characterize the interplay between genetic factors and headaches, we aimed to perform a descriptive analysis of the genetic profile in a population of headache patients, related to CYP450 enzymatic system and factors associated with vascular disease (factor V Leiden, factor II, ApoE, MTHFR and Vitamin K epoxide reductase complex subunit 1 (VQORC1)). Ensuing, we aimed to compare our results with data deriving from the general population.

\section{Methods}

A retrospective descriptive and analytical study was performed after obtaining approval from the Cedars-Sinai Institutional Review Board. Medical records pertaining of consecutive patients that presented to our Headache Clinic with a chief complaint of headache and/or facial pain and underwent PersonaGene ${ }^{\mathrm{TM}}$ genetic testing between January and December 2013 were reviewed. Demographic data (age, gender and race), headache diagnosis and genetic testing results were collected.

For genetic testing, two buccal swabs were obtained for each patient and sent to American International Biotechnology (AIB). DNA extraction, library preparation and ion torrent sequencing were performed based on the previously published standard procedure [8]. Next generation sequencing with the Ion Torrent 
PGM was used to genotype the genes of interest. The data for the CYP450 genes was released in the format of poor, intermediate, normal or rapid metabolizer. For Factors II and V Leiden and MTHFR gene mutation analysis, the results were conveyed as detected heterozygous, detected homozygous or none detected. ApoE results were reported as low (E3E3), intermediate (E2E2, E2E3) or high (E2E4, E3E4, E4E4) cardiovascular risk. VQORC1 analysis was interpreted as low, intermediate or high sensitivity. Specifically, a promoter region polymorphism (VKORC1 $-1639 \mathrm{G}>\mathrm{A}$ ) that previously had been associated with warfarin sensitivity was studied [9].

The genetic data from our headache cohort was subsequently compared with to genetic data from the general population obtained from the AIB.

\section{Statistical Methods}

Descriptive statistics were reported for all patients as well as the migraine and non-migraine cohorts. Categorical variables were reported in terms of frequencies. Chi-square and Fisher's exact tests were used to compare all headache, migraine and non-migraine patients with the general population estimates. A two-tailed p-value less than 0.05 was statistically significant. All statistical analyses were conducted using SAS 9.3 (SAS Institute, Cary, NC, USA).

\section{Results}

Oral swabs were collected from a total of 130 patients with a headache diagnosis for the purpose of the genetic testing. Age range at the time of diagnosis was 46 to 69 years, with a mean of 55.7 and a median age of 58 years. $80 \%$ of patients were female. $93.1 \%$ of them were Caucasian, 3.6\% Hispanic, $2.3 \%$ African American and $0.8 \%$ Asian.

The patients were given one or multiple diagnoses of headache and facial pain, based on standard definitions as per International Classification of Headache Disorders $3^{\text {rd }}$ edition. Whereas $56.9 \%$ of patients had only one diagnosis, $19.2 \%$ had two, $13.8 \%$ three, $6.9 \%$ four and $3.1 \%$ had five diagnoses. The most common diagnosis was migraine headache without aura (66.9\%), followed by myofascial pain and trigeminal neuralgia (Table 1 ).

Out of 91 patients that had a diagnosis of migraine $(70.8 \%$ of the patient population), $85 \%$ were female (mean age 52.2; median age 55; range 42 - 67 years). $91 \%$ of them were Caucasian, 5.4\% Hispanic, 2.2\% African American and 1.1\% Asian. $52.7 \%$ of patients with migraine had at least one additional diagnosis (Table 1). Myofascial pain was the most common associated diagnosis and was present in $39 \%$ of cases, followed by medication overuse headache $(15 \%)$ and cervicogenic pain (13\%).

Most patients with headaches were prescribed medications from at least two categories. The category of prescribed medications varied in the entire headache cohort, as well as in the subgroups of patients with migraine and non-migraine headaches (Table 2). The most common prescribed medication 
Table 1. Demographics, headache diagnosis, and number of multiple concomitant diagnoses.

\begin{tabular}{|c|c|c|c|}
\hline Diagnosis, N (\%) & $\begin{array}{l}\text { Headache patients } \\
\qquad(\mathrm{N}=130)\end{array}$ & $\begin{array}{l}\text { Migraine patients } \\
\qquad(\mathrm{N}=91)\end{array}$ & $\begin{array}{c}\text { Non-Migraine } \\
\text { patients }(\mathrm{N}=39)\end{array}$ \\
\hline \multicolumn{4}{|l|}{ Age at diagnosis, years } \\
\hline mean $(\mathrm{SD})$ & $55.7(17.6)$ & $52.3(18.3)$ & $63.7(13.0)$ \\
\hline median [IQR] & $58[46-69]$ & $52[42-67]$ & $64[55-75]$ \\
\hline Female gender, $\mathrm{N}(\%)$ & $104(80.0)$ & $78(85.7)$ & $26(66.7)$ \\
\hline \multicolumn{4}{|l|}{ Race, $\mathrm{N}(\%)^{*}$} \\
\hline White & $121(93.1)$ & $83(91.2)$ & $38(97.4)$ \\
\hline African American & $3(2.3)$ & $2(2.2)$ & $1(2.6)$ \\
\hline Hispanic & $5(3.6)$ & $5(5.5)$ & $0(0)$ \\
\hline Asian & $1(0.8)$ & $1(1.1)$ & $0(0)$ \\
\hline \multicolumn{4}{|l|}{ Diagnosis, N (\%) } \\
\hline Migraine without aura & 87 (66.9) & $87(95.6)$ & not applicable \\
\hline Myofascial pain & $43(33.1)$ & $35(38.5)$ & $8(20.5)$ \\
\hline Trigeminal neuralgia & $27(20.8)$ & $2(2.2)$ & $25(61.1)$ \\
\hline Cervicogenic pain & $16(12.3)$ & $12(13.2)$ & $4(10.3)$ \\
\hline Temporomandibular joint disorder & $16(12.3)$ & $10(10.9)$ & $7(18.0)$ \\
\hline Medication overuse headache & $14(10.8)$ & $13(14.3)$ & $1(2.6)$ \\
\hline Migraine with aura & $4(3.1)$ & $4(4.4)$ & not applicable \\
\hline Post-herpetic neuralgia & $4(3.1)$ & $1(1)$ & $3(7.7)$ \\
\hline Posttraumatic headache & $4(3.1)$ & $1(1)$ & $0(0)$ \\
\hline Cluster headache & $3(2.3)$ & $2(2.2)$ & $1(2.6)$ \\
\hline Hemicrania continua & $3(2.3)$ & $2(2.2)$ & $1(2.6)$ \\
\hline Burning mouth syndrome & $2(2.3)$ & $0(0)$ & $3(7.7)$ \\
\hline Hypnic headache & $2(2.3)$ & $2(2.2)$ & $0(0)$ \\
\hline Dysgeusia & $1(0.8)$ & $0(0)$ & $1(2.6)$ \\
\hline Temporal arteritis & $1(0.8)$ & $1(1.1)$ & $0(0)$ \\
\hline Complex regional pain syndrome & $1(0.8)$ & $1(1.1)$ & $0(0)$ \\
\hline Low-pressure headache & $1(0.8)$ & $1(1.1)$ & $0(0)$ \\
\hline Exertional headache & $1(0.8)$ & $1(1)$. & $0(0)$ \\
\hline Chronic paroxysmal hemicrania & $1(0.8)$ & $1(1.1)$ & $0(0)$ \\
\hline SUNCT & $1(0.8)$ & $0(0)$ & $1(2.6)$ \\
\hline Nummular headache & $1(0.8)$ & $1(1.1)$ & $0(0)$ \\
\hline \multicolumn{4}{|c|}{ Number of concomitant diagnoses, $\mathrm{N}(\%)$} \\
\hline 1 & $73(56.2)$ & $43(47.3)$ & $30(76.9)$ \\
\hline 2 & $26(20.0)$ & $23(25.3)$ & $3(7.7)$ \\
\hline 3 & $19(14.6)$ & $14(15.4)$ & $5(12.8)$ \\
\hline 4 & $8(6.2)$ & $7(7.7)$ & $1(2.6)$ \\
\hline 5 & $4(3.1)$ & $4(4.4)$ & $0(0)$ \\
\hline
\end{tabular}

${ }^{*}$ Not applicable since diagnosis involves migraine and this column corresponds to non-migraine patients. SUNCT $=$ Short-lasting unilateral neuralgiform headache with conjunctival injection and tearing. 
Table 2. Category of headache medications and number of medical trials.

\begin{tabular}{|c|c|c|c|}
\hline Medication categories, N (\%) & $\begin{array}{l}\text { Headache Patients } \\
\qquad(\mathrm{N}=130)\end{array}$ & $\begin{array}{l}\text { Migraine patients } \\
\qquad(\mathrm{N}=91)\end{array}$ & $\begin{array}{c}\text { Non-Migraine } \\
\text { patients }(\mathrm{N}=39)\end{array}$ \\
\hline Antiepiletic drugs & $92(70.8)$ & $64(70.3)$ & $28(71.8)$ \\
\hline Triptans & $47(36.2)$ & $41(45.1)$ & $6(15.4)$ \\
\hline NSAIDS & $40(30.8)$ & $32(35.2)$ & $8(20.5)$ \\
\hline Tricyclic antidepressants & $47(36.2)$ & $33(36.3)$ & $14(35.9)$ \\
\hline SNRIs & $40(30.8)$ & $28(30.8)$ & $12(30.8)$ \\
\hline Opioids & $33(25.4)$ & $23(25.3)$ & $10(25.6)$ \\
\hline Beta blockers & $36(27.7)$ & $32(35.2)$ & $4(10.3)$ \\
\hline Botox & $27(20.8)$ & $25(27.5)$ & $2(5.1)$ \\
\hline Benzodiazepines & $23(17.7)$ & $10(11.0)$ & $13(33.3)$ \\
\hline Memantine & $22(16.9)$ & $19(20.9)$ & $3(7.7)$ \\
\hline Muscle relaxants & $18(13.9)$ & $12(13.2)$ & $6(15.4)$ \\
\hline SSRIs & $18(13.9)$ & $15(16.5)$ & $3(7.7)$ \\
\hline \multicolumn{4}{|l|}{ Number of medication categories } \\
\hline 1 & $20(15.4)$ & $11(12.1)$ & $9(23.1)$ \\
\hline 2 & $25(19.2)$ & $17(18.9)$ & $9(20.5)$ \\
\hline 3 & $28(21.5)$ & $19(20.9)$ & $9(23.1)$ \\
\hline 4 & $24(18.5)$ & $15(15.5)$ & $9(23.1)$ \\
\hline 5 & $13(10.0)$ & $10(11.0)$ & $9(23.1)$ \\
\hline 6 & $13(10.0)$ & $12(13.2)$ & $9(23.1)$ \\
\hline 7 & $6(4.6)$ & $6(6.6)$ & $23(7.7)$ \\
\hline 8 & $1(0.8)$ & $1(1.1)$ & $1(2.6)$ \\
\hline
\end{tabular}

NSAIDS = Nonsteroidal Anti-inflammatory Drugs; SNRIs = Serotonin and Norepinephrine Reuptake inhibitors; SSRIs = Selective Serotonin Reuptake Inhibitors.

class was epileptic drugs.

Given Caucasians were predominant in our cohort of headache patients (93.1\%), we compared the genetic information from our Caucasian patients $(\mathrm{n}=$ 121) and the general population Caucasian-derived data from the ABI database $(\mathrm{n}=11,500)$. CYP450 genotyping was significantly different in our cohort of headache patients, as well as the subgroup of migraine patients, when compared to the general population for CYP3A4, CYP3A5, CYP2D6 and VQORC1 (Table 3). Headache patients were otherwise comparable to the general population for CYP2C9 and CYP2C19 (Table 3). More headache patients were high metabolizers for CYP3A4 $(\mathrm{p}<0.001)$ and CYP3A5 $(\mathrm{p}<0.0001)$ and less headache patients were normal metabolizers for CYPA34 $(\mathrm{p}=0.01)$ when compared to general population. More headache patients were normal metabolizers for CYP3A5 ( $\mathrm{p}<$ 0.0001), and none of our headache patients was poor metabolizer for CYP3A5. Headache cohort, all migraine and migraine without aura cohorts behaved 
similarly regarding CYP genotyping. Significantly fewer Caucasian headache patients were high (9.2 vs 38.9, p $<0.001$ for headache; 8.6 vs 38.9, $\mathrm{p}<0.001$ for migraine), intermediate ( 14.3 vs $47.5, \mathrm{p}<0.001$ for headache; 18.5 vs $47.5, \mathrm{p}<$ 0.001 for migraine) and poor ( 5 vs $13.6, \mathrm{p}<0.001$ for headache; 7.4 vs $13.6, \mathrm{p}<$

Table 3. Comparisons of CYP genotyping between patient cohorts and the general patient population (White Patients Only).

\begin{tabular}{|c|c|c|c|c|c|c|c|}
\hline & \multicolumn{4}{|c|}{ Patient Cohort } & \multicolumn{3}{|c|}{$\mathrm{P}$ value for comparisons with general population } \\
\hline & $\begin{array}{l}\text { All Patients } \\
\mathrm{N}=121\end{array}$ & $\begin{array}{l}\text { All Migraine } \\
\qquad \mathrm{N}=83\end{array}$ & $\begin{array}{l}\text { All Migraine w/out } \\
\text { aura } \mathrm{N}=80\end{array}$ & $\begin{array}{c}\text { General } \\
\text { Population }\end{array}$ & All patients & $\begin{array}{l}\text { Migraine } \\
\text { patients }\end{array}$ & $\begin{array}{l}\text { Migraine w/out } \\
\text { aura patients }\end{array}$ \\
\hline СYР4502C9 & & & & & 0.6266 & 0.4845 & 0.3539 \\
\hline high & $0(0)$ & $0(0)$ & $0(0)$ & $0(0)$ & 1.00 & 1.00 & 1.00 \\
\hline intermediate & $40(33.1)$ & $26(31.3)$ & $23(28.8)$ & $3933(33.2)$ & 0.9641 & 0.7265 & 0.4058 \\
\hline normal & $76(62.8)$ & $53(63.9)$ & $53(66.2)$ & $7593(64.1)$ & 0.7690 & 0.9634 & 0.6892 \\
\hline poor & $5(4.1)$ & $4(4.8)$ & $4(5.0)$ & $320(2.7)$ & 0.3874 & 0.2897 & 0.1726 \\
\hline CYP3A4 & & & & & $<0.0001$ & $<0.0001$ & $<0.0001$ \\
\hline intermediate & $12(9.9)$ & $8(9.6)$ & $7(8.8)$ & $776(7.4)$ & 0.3030 & 0.4479 & 0.6571 \\
\hline normal & $104(86.0)$ & $71(85.5)$ & $69(86.2)$ & $9600(92.1)$ & 0.0138 & 0.0292 & 0.0562 \\
\hline poor & $0(0)$ & $0(0)$ & $0(0)$ & $52(0.5)$ & 1.00 & 1.00 & 1.00 \\
\hline CYP3A5 & & & & & $<0.0001$ & $<0.0001$ & $<0.0001$ \\
\hline high & $6(5.0)$ & $5(6.0)$ & $5(6.3)$ & $0(0)$ & $<0.0001$ & $<0.0001$ & $<0.0001$ \\
\hline intermediate & $12(9.9)$ & $8(9.6)$ & $7(8.7)$ & $1373(13.2)$ & 0.02829 & 0.3343 & 0.252 \\
\hline normal & $103(851)$ & $70(84.3)$ & $68(85.0)$ & $68(0.7)$ & $<0.0001$ & $<0.0001$ & $<0.0001$ \\
\hline poor & $0(0)$ & $0(0)$ & $0(0)$ & $8938(86.1)$ & & & \\
\hline CYP2D6 & & & & & $<0.0001$ & $<0.0001$ & $<0.0001$ \\
\hline intermediate & $17(14.3)$ & $15(18.5)$ & $14(18.0)$ & $5601(47.5)$ & $<0.0001$ & $<0.0001$ & $<0.0001$ \\
\hline normal & $85(71.4)$ & $53(65.4)$ & $52(66.7)$ & $0(0)$ & $<0.0001$ & $<0.0001$ & $<0.0001$ \\
\hline poor & $6(5.0)$ & $6(7.4)$ & $5(6.4)$ & $1604(13.6)$ & $<0.0001$ & $<0.0001$ & $<0.0001$ \\
\hline CYPC19 & & & & & 0.1971 & 0.2962 & 0.3473 \\
\hline high & $36(29.8)$ & $26(31.7)$ & $26(32.9)$ & $3702(31.2)$ & 0.733 & 0.97979 & 0.8019 \\
\hline intermediate & $32(26.4)$ & $21(25.6)$ & $20(25.3)$ & $2326(19.6)$ & 0.0595 & 0.1927 & 0.2257 \\
\hline normal & $47(38.8)$ & $32(39.0)$ & $31(38.8)$ & 4854 (40.9) & 0.6465 & 0.6644 & 0.6962 \\
\hline poor & $6(5.0)$ & $3(3.7)$ & $3(3.8)$ & $985(8.3)$ & 0.1842 & 0.1244 & 0.1408 \\
\hline $\mathrm{VKORC1}^{*}$ & & & & & 0.0375 & 0.0254 & 0.0323 \\
\hline high & $10(8.3)$ & $6(7.3)$ & $6(7.6)$ & $1625(14.1)$ & 0.0693 & 0.0772 & 0.0961 \\
\hline intermediate & $72(60.0)$ & $52(63.4)$ & $50(63.3)$ & $5644(49.1)$ & 0.0172 & 0.0096 & 0.0118 \\
\hline low & $38(31.7)$ & $24(29.3)$ & $23(29.1)$ & $4232(36.8)$ & 0.2462 & 0.1588 & 0.1581 \\
\hline
\end{tabular}

${ }^{\star}$ Sensitivity level. $\mathrm{CY}=$ Cytochrome; $\mathrm{VKORC} 1=$ Vitamin $\mathrm{K}$ epoxide reductase complex subunit 1. 
0.001 for migraine) metabolizers under CYP2D6 pathways when compared to the general Caucasian population cohort. Patients with headaches and migraines were more likely to show intermediate sensitivity to warfarin (63.4 vs $49.1, \mathrm{p}=$ 0.009) based on VQORC1 testing.

$21.5 \%$ of Caucasian headache patients were detected MTHFR heterozygote and $14.9 \%$ were homozygous mutant. These percentages were not significantly different compared to the general Caucasian population (Table 4). $9.1 \%$ of headache patients had intermediate and $23.1 \%$ had high cardiovascular risk based on ApoE testing. The overall ApoE genotyping of the headache and migraine patients was statistically different compared to the general population (Table 4). Statistically significant less headache and migraine patients had low cardiovascular risk $(67.8$ vs $83.8, \mathrm{p}<0.001$ for headache and 68.7 vs $83.8, \mathrm{p}=$ 0.002 for migraine) and significantly more headache and migraine patients had high cardiovascular risk compared to the general population controls $(\mathrm{p}<$ 0.0001).

$0.8 \%$ of headache patients and $1.2 \%$ of migraineurs were homozygote, whereas

Table 4. Comparison between patient cohorts and the general population for Apo genotyping, Factor II, and Factor V Leiden, and MTHRF status. (White Patients Only).

\begin{tabular}{|c|c|c|c|c|c|c|c|}
\hline & \multicolumn{4}{|c|}{ Patient Cohort } & \multicolumn{3}{|c|}{$\begin{array}{l}\text { P value for comparisons with general } \\
\text { population }\end{array}$} \\
\hline & $\begin{array}{l}\text { All Patients } \\
\mathrm{N}=121\end{array}$ & $\begin{array}{l}\text { All Migraine } \\
\qquad \mathrm{N}=83\end{array}$ & $\begin{array}{c}\text { All Migraine } \\
\text { w/out aura } \\
\mathrm{N}=80\end{array}$ & $\begin{array}{c}\text { General } \\
\text { Population }\end{array}$ & All patients & $\begin{array}{l}\text { Migraine } \\
\text { patients }\end{array}$ & $\begin{array}{c}\text { Migraine } \\
\text { w/out aura } \\
\text { patients }\end{array}$ \\
\hline ApoE (CVD risk) & & & & & $<0.0001$ & $<0.0001$ & $<0.0001$ \\
\hline Low & $82(67.8)$ & $57(68.7)$ & $54(67.5)$ & $7342(83.8)$ & $<0.0001$ & 0.0002 & $<0.0001$ \\
\hline Intermediate & $11(9.1)$ & $10(12.1)$ & $10(12.5)$ & $1424(16.2)$ & 0.0330 & 0.2984 & 0.3618 \\
\hline High & $28(23.1)$ & $16(19.3)$ & $16(20.0)$ & $0(0)$ & $<0.0001$ & $<0.0001$ & $<0.0001$ \\
\hline Factor II & & & & & 0.6055 & 1.00 & 1.00 \\
\hline Detected heterozygote & $2(1.7)$ & $2(2.4)$ & $2(2.5)$ & $810(3.2)$ & 0.4439 & 1.00 & 1.00 \\
\hline Detected homozygote & $0(0)$ & $0(0)$ & $0(0)$ & $10(0.04)$ & 1.00 & 1.00 & 1.00 \\
\hline Not detected & $119(98.3)$ & $81(97.6)$ & $78(97.5)$ & $24,313(96.7)$ & 0.4439 & 1.00 & 1.00 \\
\hline Factor V Leiden & & & & & 0.0066 & 0.0004 & 0.0003 \\
\hline Detected heterozygote & $9(7.4)$ & $7(8.4)$ & $7(8.7)$ & $1270(5.1)$ & 0.2325 & 0.1995 & 0.1213 \\
\hline Detected homozygous mutant & $1(0.8)$ & $1(1.2)$ & $1(1.3)$ & $19(0.08)$ & 0.0916 & 0.0638 & 0.0616 \\
\hline Not detected & $111(91.7)$ & $75(90.4)$ & $72(90.0)$ & $23,847(94.9)$ & 0.1192 & 0.0757 & 0.0676 \\
\hline MTHFR & & & & & 0.0063 & 0.0026 & 0.0029 \\
\hline Detected heterozygote & $26(21.5)$ & $18(21.7)$ & $18(22.5)$ & $5522(22.0)$ & 0.8988 & 0.9508 & 0.9086 \\
\hline Detected homozygous mutant & $18(14.9)$ & $14(16.9)$ & $13(16.3)$ & $3127(12.4)$ & 0.4181 & 0.2226 & 0.3028 \\
\hline Not detected & $76(62.8)$ & $50(60.2)$ & $48(60.0)$ & $16,488(65.6)$ & 0.5204 & 0.3056 & 0.2932 \\
\hline
\end{tabular}

ApoE = Apolipoprotein E; CVD = Cardiovascular; MTHFR = Methylene tetrahydrofolate reductase. 
$7.4 \%$ of headache and $8.4 \%$ of migraine patients were heterozygote for Factor $\mathrm{V}$ Leiden mutation. The overall distribution of Factor $\mathrm{V}$ Leiden was found to be statistically different between headache and migraine patients and general population subjects ( $\mathrm{p}$ values of 0.006 and 0.0004 respectively) (Table 4). Heterozygote state for prothrombin mutation was detected in $1.7 \%$ of headache and $2.4 \%$ of migraine patients; no headache patient was detected homozygote for Factor II mutation. Factor II characteristics in our cohort of headache patients were not different than the general population data (Table 4).

\section{Discussion}

Our headache and facial pain patient cohort description revealed that the most common diagnosis in a Headache Clinic remains migraine without aura and most patients are middle-aged females. Most headache patients were prescribed multiple medications with at least two different mechanisms of action. Our study conveys novel genetic information in headache patients regarding CYP450 metabolic pathways and certain factors involved in the vascular genetic linkage.

Although many genetic studies have described various target genes on pain sensitivity and/or analgesic dosing requirements [10], pharmacogenomics in headache medicine is still in its infancy [11]. CYP genotyping has been shown to predict most aberrant phenotypes. Despite this, it is currently rarely performed in clinical practice, particularly in prescribing medications for neurologic conditions. Given the ease and accessibility of genetic testing for CYP polymorphisms, some clinicians suggest these tests should be more commonly utilized in clinical practice. Depending on the genetic makeup of the CYP450 system in a person, the metabolic activity of a CYP450 enzyme can be categorized as poor (experiencing no clinical effect from the drug), intermediate, extensive or ultra-rapid (experiencing toxic drug effects). Although individual variability in CYP enzyme activity may be caused by various factors, genetic polymorphisms is the most important factor and the main reason for drug therapy failure and side effects [12].

A recent clinical pharmacogenomics study of the CYP2 family [8], including 30.000 participants, showed evidence for large range of genetic variation within and between various ethnic groups. For instance, $5 \%$ - 14\% of Caucasians, $0 \%-$ $5 \%$ of African Americans and 0\% - 1\% of Asians are poor metabolizers of drugs dependent on CYP2D6, which includes beta blockers, tricyclic antidepressants, triptans and opioids. Mattson et al. [13] reported no difference in the distribution of CYP2D6 phenotype in migraineurs compared to general population controls. In contrast, our Caucasian headache patients and the migraine subgroup were different than the general Caucasian population, with significantly lower percentages of headache patients being high, intermediate and poor metabolizers under CYP2D6 pathway.

Our headache patients showed significantly different CYP3A4/CYP3A5 genotypes compared to general population, with more headache patients being 
high metabolizers. CYP3A enzymes play a dominant role in the metabolic elimination of more headache drugs than any other biotransformation enzyme, likely due to a large active site that permits the binding of structurally diverse molecules [14]. CYP3A5 pathway is involved in calcium channel, sodium channel blockers and tricyclic antidepressants metabolism. CYP3A4 pathway is involved in the metabolism of a large group of analgesics, including serotonin/norepinephrine reuptake inhibitors, triptans, calcium and sodium channel blockers, topiramate, tricyclic antidepressants, anti-dopamine/serotonin agents, dihydroergotamine.

CYP2C19 pathway is involved in the metabolic activity of tricyclic antidepressants, beta-blockers, sodium channel blockers, anti-dopamine/serotonin agents, topiramate and synthetic opioids. The presence of one or two non-functional alleles has been shown to have an increased risk of adverse cardiovascular events to drugs such as clopidogrel [15], therefore its genotyping was proposed to be considered in patients with depression and cardiovascular disease. CYP2C9 activity affects the metabolism of a variety of drugs including the tricyclic antidepressants, sodium channel blockers, non-steroidal anti-inflammatories and valproic acid. In addition, the influence of specific CYP2C9 genotypes on warfarin dose requirements was reported in the literature [16]. Notably, no differences in CYP2C19 and CYP2C9 phenotypes were noticed between our Caucasian headache and migraine patients and the general population.

VKORC1 gene polymorphism was shown to be significantly associated with the variation of inter-individual warfarin dose requirement variation [17]. The warfarin mean daily dose has been shown to decrease as a function of CYP2C9 and VKORC1 genotype, which accounts for approximately $40 \%$ of variability in warfarin dosing [18]. The same study showed that CYP2C9 and VKORC1 genotyping, together with patient age and height can account for $55 \%$ of the dosing variability. Based on pharmacogenomics studies [19], a range of Expected Therapeutic Warfarin Dose based on CYP2C9 and VKORC1 Genotypes were newly labeled by Food and Drug Administration. Our Caucasian headache cohort was significantly different in VQORC genotyping than the general population ( $\mathrm{p}=$ $0.03)$. A significantly higher percentage of patients with headaches and migraines had intermediate sensitivity to warfarin when compared to general population ( $\mathrm{p}=0.01$ and respectively 0.009 ) and a lower number of patients with migraines had high sensitivity to warfarin $(p=0.07)$. The significance of these results needs to be well thought on when initiating anticoagulation in patients with headaches.

Given most patients with headaches are prescribed several medications, pharmacogenomic studies and CYP genotyping should be considered at the very least in patients that fail multiple medication trials, to determine better drug choices and interactions with other concomitant drugs. We did not aim to correlate genetic profiles with response to specific therapies in this study.

Prothrombotic factors, like Factor V Leiden, prothrombin factor, elevations in 
von Willebrand factor antigen and activity, MTHFR, and ACE D/I polymorphisms were hypothesized to play a role in the link between migraine and vascular risk [6], but their roles in headaches in general is not well defined.

ApoE is recognized for its importance in cardiovascular disease and cognition. ApoE is polymorphic with three major isoforms, which translate into three alleles of the gene. ApoE2 is associated with a greater risk for early vascular disease and migraines. ApoE4 is associated with increased plasma cholesterol levels and subsequent increased risk for coronary heart disease. ApoE4/E4 is considered to be protective against migraine and tension-type headache [20]. In our cohort, most patients with headache and migraine had low cardiovascular risk based on ApoE testing. However, when compared to the general population, a significantly lower percentage of headache and migraine patients had low cardiovascular risk. $23.1 \%$ of headache patients and $19.3 \%$ of the migraineurs had high cardiovascular risk and this percentage was significantly higher compared to the general population.

Factor V Leiden mutation causes primary and recurrent thromboembolism. This disorder is most common among ethnic Europeans and its frequency in the US population is $4 \%-6 \%$ [21]. Despite Factor V Leiden's known association with increased vascular risk [22], a recent meta-analysis showed that isolate factor $\mathrm{V}$ Leiden and prothrombin gene mutation play a negligible pathogenic role in migraine in adults [23]. Factor V Leiden in our Caucasian cohort of headache and migraine were significantly different than the general population controls.

Different ApoE and Factor V profiles in our cohort could be hypothetically linked to the increased vascular risk in migraine patients, which are in line with prior reports [6]. However, why patients with other headache types (and so potentially with different etiology than neurovascular) have disparate ApoE and Factor V profiles and thus different vascular risk than the general population, is currently not elucidated. Conversely, we observed no significant differences between our headache and migraine patients and the general population regarding MTHFR genotype and prothrombin G20210A mutation, factors that were shown to be associated with an increased risk for migraine with aura [24] and cerebrovascular conditions [25]. Further research is needed to define the pathophysiological mechanisms underlying different headache types, as well as vascular risk profile associated with headache subtypes.

This is the first study to report genetic data in a cohort of patients with headache and facial pain, to our knowledge. The small number of patients that underwent PersonaGene ${ }^{\mathrm{TM}}$ testing and a single study site limits the interpretation of our findings and their broad generalizability. Another limitation is that the clear majority of our patients (91.2\%) were Caucasian. While each gene is known to show a different pattern of distribution across ethnic groups, we report comparisons data pertinent to only Caucasian patients with headaches. Lastly, the heterogeneity in the headache diagnoses limits the interpretation of the findings, however the predominant diagnosis was migraine without aura and 
comparative analysis for migraine only cohort was performed.

\section{Conclusion}

We observed significant CYP3A4, CYP3A5 and CYP2D6 genotyping differences between patients with headaches and the general population, which need to be carefully considered when initiating therapies in Caucasian headache patients. Future pharmacogenomic research lines are directed to identify the right drug for the right individual, while helping to prevent adverse drug reactions. Different sensitivities to warfarin in headache patients based on VQORC1 genotyping should raise an alarm signal when managing anticoagulation in this patient population. The significant differences in ApoE and Factor V Leiden between patients with headache and general population also provoke forthcoming research addressing strategies to decrease their risk for vascular comorbidities.

\section{References}

[1] Burstein, R., Noseda, R. and Borsook, D. (2015) Migraine: Multiple Processes, Complex Pathophysiology. Journal of Neuroscience, 35, 6619-6629. https://doi.org/10.1523/JNEUROSCI.0373-15.2015

[2] Piane, M., et al. (2007) Genetics of Migraine and Pharmacogenomics: Some Considerations. The Journal of Headache and Pain, 8, 334-339. https://doi.org/10.1007/s10194-007-0427-2

[3] Bigal, M.E., et al. (2009) Migraine and Cardiovascular Disease: Possible Mechanisms of Interaction. Neurology, 72, 1864-1871. https://doi.org/10.1212/WNL.0b013e3181a71220

[4] Monteith, T.S., et al. (2015) Migraine and Risk of Stroke in Older Adults: Northern Manhattan Study. Neurology, 85, 715-721. https://doi.org/10.1212/WNL.0000000000001854

[5] Persico, A.M., et al. (2015) Migraine Genetics: Current Findings and Future Lines of Research. Neurogenetics, 16, 77-95. https://doi.org/10.1007/s10048-014-0433-x

[6] Sacco, S. and Kurth, T. (2014) Migraine and the Risk for Stroke and Cardiovascular Disease. Current Cardiology Reports, 16, 524. https://doi.org/10.1007/s11886-014-0524-1

[7] Samer, C.F., et al. (2013) Applications of CYP450 Testing in the Clinical Setting. Molecular Diagnosis \& Therapy, 17, 165-184. https://doi.org/10.1007/s40291-013-0028-5

[8] Budd, W.T., et al. (2016) Next Generation Sequencing Reveals Disparate Population Frequencies among Cytochrome P450 Genes: Clinical Pharmacogenomics of the CYP2 Family. International Journal of Computational Biology and Drug Design (IJCBDD), 9, 54-77. https://doi.org/10.1504/IJCBDD.2016.074984

[9] Geisen, C., et al. (2005) VKORC1 Haplotypes and Their Impact on the Inter-Individual and Inter-Ethnical Variability of Oral Anticoagulation. Thrombosis and Haemostasis, 94, 773-779.

[10] Smith, M.T. and Muralidharan, A. (2012) Pharmacogenetics of Pain and Analgesia. Clinical Genetics, 82, 321-330. https://doi.org/10.1111/j.1399-0004.2012.01936.x

[11] Trescot, A.M. and Faynboym, S. (2014) A Review of the Role of Genetic Testing in Pain Medicine. Pain Physician, 17, 425-445. 
[12] Zhou, S.F. (2009) Polymorphism of Human Cytochrome P450 2 D6 and Its Clinical Significance: Part II. Clinical Pharmacokinetics, 48, 761-804. https://doi.org/10.2165/11318070-000000000-00000

[13] Mattsson, P., et al. (2000) Cytochrome P450 2D6 and Glutathione S-Transferase M1 Genotypes and Migraine. European Journal of Clinical Investigation, 30, 367-371. https://doi.org/10.1046/j.1365-2362.2000.00633.x

[14] Lamba, J.K., et al. (2002) Genetic Contribution to Variable Human CYP3A-Mediated Metabolism. Advanced Drug Delivery Reviews, 54, 1271-1294. https://doi.org/10.1016/S0169-409X(02)00066-2

[15] Sim, S.C., et al. (2006) A Common Novel CYP2C19 Gene Variant Causes Ultrarapid Drug Metabolism Relevant for the Drug Response to Proton Pump Inhibitors and Antidepressants. Clinical Pharmacology \& Therapeutics, 79, 103-113. https://doi.org/10.1016/j.clpt.2005.10.002

[16] Lindh, J.D., et al. (2009) Influence of CYP2C9 Genotype on Warfarin Dose Requirements-A Systematic Review and Meta-Analysis. European Journal of Clinical Pharmacology, 65, 365-375. https://doi.org/10.1007/s00228-008-0584-5

[17] Chan, K.W., et al. (2010) Magnetic Resonance Spectroscopy of the Brain under Mild Hypothermia Indicates Changes in Neuroprotection-Related Metabolites. Neuroscience Letters, 475, 150-155. https://doi.org/10.1016/j.neulet.2010.03.066

[18] Rieder, M.J., et al. (2005) Effect of VKORC1 Haplotypes on Transcriptional Regulation and Warfarin Dose. The New England Journal of Medicine, 352, 2285-2293. https://doi.org/10.1056/NEJMoa044503

[19] Gage, B.F., et al. (2008) Use of Pharmacogenetic and Clinical Factors to Predict the Therapeutic Dose of Warfarin. Clinical Pharmacology \& Therapeutics, 84, 326-331. https://doi.org/10.1038/clpt.2008.10

[20] Gupta, R., et al. (2009) Polymorphism in Apolipoprotein E among Migraineurs and Tension-Type Headache Subjects. The Journal of Headache and Pain, 10, 115-120. https://doi.org/10.1007/s10194-008-0094-y

[21] Price, D.T. and Ridker, P.M. (1997) Factor V Leiden Mutation and the Risks for Thromboembolic Disease: A Clinical Perspective. Annals of Internal Medicine, 127, 895-903. https://doi.org/10.7326/0003-4819-127-10-199711150-00007

[22] Kim, R.J. and Becker, R.C. (2003) Association between Factor V Leiden, Prothrombin G20210A, and Methylenetetrahydrofolate Reductase C677T Mutations and Events of the Arterial Circulatory System: A Meta-Analysis of Published Studies. American Heart Journal, 146, 948-957. https://doi.org/10.1016/S0002-8703(03)00519-2

[23] Lippi, G., Mattiuzzi, C. and Cervellin, G. (2015) Meta-Analysis of Factor V Leiden and Prothrombin G20210A Polymorphism in Migraine. Blood Coagulation \& Fibrinolysis, 26, 7-12. https://doi.org/10.1097/MBC.0000000000000188

[24] Schürks, M., Rist, P.M. and Kurth, T. (2010) MTHFR 677C>T and ACE D/I Polymorphisms in Migraine: A Systematic Review and Meta-Analysis. Headache, 50, 588-599. https://doi.org/10.1111/j.1526-4610.2009.01570.x

[25] Nguyen, A. and Prothrombin, G. (2000) A Polymorphism and Thrombophilia. Mayo Clinic Proceedings, 75, 595-604. https://doi.org/10.4065/75.6.595 